\title{
Designing Mangrove Ecology Self-Learning Application Based on a Micro-Learning Approach
}

\author{
https://doi.org/10.3991/ijet.v15i11.12585 \\ Supaporn Chai-Arayalert ${ }^{(\varpi)}$, Supattra Puttinaovarat \\ Prince of Songkla University, Surat Thani, Thailand \\ supaporn.chaiepsu.ac.th
}

\begin{abstract}
The development of a mangrove ecology self-learning application integrates the advantages of mobile-based learning and the benefits of microlearning into the virtual learning of mangrove ecology. The system was designed based on a case study in the Leeled mangrove forest, Thailand and encourages young learners to understand the value of mangrove forests, and to help to preserve them. The system developed uses a virtual learning environment and accommodates young learner's behaviours, favouring micro-learning with the content organized into the learning units which take a maximum of 15 minutes to complete. The application therefore allows the learning to be integrated into the learners' daily activities and can contribute to their lifelong learning. It allows learners to conduct self-learning and gain experience from performance in a virtual environment which simulates a real mangrove forest. This approach is better suited to the needs of present-day young people than traditional approaches to environmental education.
\end{abstract}

Keywords-Micro-learning, Mangrove ecology, Design thinking.

\section{Introduction}

Mangrove forests are coastal intertidal areas in tropical countries e.g., Indonesia, Malaysia, the Philippines and Thailand. Globally, including in Thailand, mangrove forests are under attack for various reasons which is causing a reduction of such forests, particularly due to human population expansion and human activities, which have had a strong impact in the diminution of mangrove forest resources. However, a major cause is insufficient knowledge being provided to the public on the value of mangrove forests and the need to protect them. Whereas some contents have been offered, they are not interesting enough to engage people's full attention or they might not align with their behaviours which results in further inappropriate utilization of mangrove forests. The effects are not confined to local communities and societies but also directly affects the country's economy, and the restoration of mangrove forest is becoming more difficult [1], [2].

The learning resources is crucial in environmental education since they help to make learners understand the problems and preservation methods appropriate for their local 
ecology which can contribute to sustainable development [3], [4]. By using well-designed learning resources, learners can be encouraged to understand and accept the value of mangrove forests and such learning resources can be a source of valuable knowledge relating to the care and preservation of mangrove forests. Moreover, it is reasonable to expect learners using such resources will not only be able to expand their own knowledge by seeking more relevant information on the issues involved but in due course will be able to contribute creatively to the learning media.

It has been noted that technological advances and in particular mobile devices are highly influential in the new generation's way of life and the way that younger people live, work and learn [5], [6]. Technological advances have allowed the development of micro-learning approach where the learning and understanding of content can be achieved faster, consistent with the younger generation's tendency to easily accept new things [7]-[9]. Younger people are not averse to spending an average of 9 hours consecutively each day online. This however may result in them giving less attention to things around them and the time they spend noticing such things will only occupy short periods [10], [11]. These factors are clearly influential in how young people learn and the development of learning media needs to be consistent with the younger generation's behaviours as well accommodating the technological transformation which has occurred in society. The periods occupied by such of learning are likely to be short and the means through which the learning occurs must therefore be quick, straight to the point and easy to comprehend [6], [12]. Moreover it is preferable for such learning to be focused on the use of mobile device through which learners are able to conduct selflearning based on their own interests, selecting the time and place at their own convenience and employing learning formats and features which can respond to their requirements[13]. All these ideas are aimed at helping the young generation to easily learn and comprehend the contents of life lessons.

The needs mentioned above lead naturally to the main objective of this research, which was to design a mangrove ecology application based on the micro-learning approach where learners are able to conduct self-learning. The application was constructed based on the ecology of the Leeled mangrove forest in Surat Thani province in the south of Thailand and the study's objectives included encouraging learners to perceive its ecological value and understand the need to care for it and to preserve its existence. The research was to create an appropriate method for lifelong learning which can be employed as a learning tool by learners who are unable to visit the actual mangrove forest site.

This paper begins with a literature review of previous work relating to learning regarding mangrove ecology and the evolution from traditional learning to micro-learning. That is followed by a presentation of the basic requirements for designing a mangrove ecology self-learning application based on a micro-learning approach. The following section describes the design process and the system design and is followed by discussion and a conclusion. 


\section{Related Work}

\subsection{The mangrove forest ecology}

The mangrove ecology originates from a combination of marine and land environments. A mangrove forest is an ecosystem comprised of various plants and animals living together in a surrounding of soil and both brackish and salt water. The significance of mangrove forests, such as acting as a natural barrier preventing waves in the sea from eroding the shoreline, reducing the tidal speed, facilitating the accumulation of the soil until it becomes a new piece of land, creating the new habitats for marine animals, reducing the harshness of serious storms, and filtering toxic substances from the land and thus prevent the toxins from passing into the sea [1], [14], [15].

The destruction of mangrove forest ecosystems has many causes, for example, the increasing human population and the expansion of human activities which leads to the unavoidable need to use land currently occupied by mangrove forests, illegal encroachment and consequent destruction of mangrove forests, which leads to inappropriate utilization of the forests. As can be clearly seen, the primary cause is human activity and it is imperative to organize sources of learning for the younger generation to know about, understand and hold a positive attitude about mangrove forests, and more importantly, know how to efficiently use and preserve them [1], [14], [15].

The case study on which the application developed was based was conducted at Leeled mangrove forest located in the area of Bandon Bay, Leeled sub-district, Surat Thani province. This area was selected because it is one of the richest ecosystems in the south of Thailand. The area consists of 3,162 acres located in a bay area in tidal surroundings which is being developed as a learning source supported by the local community to create opportunities for natural study. Along with a vigorous mangrove forest, the area also contains many different species of trees and provides a habitat for both land and aquatic animals [14], [16].

\subsection{The micro-learning approach}

Micro-learning is defined as short-period learning through an electronic device which can occur at any time or place [13], [17]. It is consistent with the limited duration of people's concentration span. Micro-learning assumes that people's concentration span is limited and is designed to take that into account in how content is presented. Such micro-learning represents a pattern for the development of learning now and in the future, which focuses on an informal learning style, yet is more efficient and therefore suitable for the concept of lifelong learning [18]-[20].

Micro-learning is an informal style of learning which can be undertaken in a short period of time which can make learning fun, while learners are able to gain knowledge from its activities [17], [20], [21]. With the rapid advance of digital technology, microlearning is not only powerful but also differs from traditional learning. For instance, traditional learning often entails paying high tuition fees while the learning period is 
much longer and learners may have difficulty in attending fixed classes in the transformed environment of the digital era. In contrast, micro-learning can maintain people's attention because the learning occurs through a more rapid process and can provide learners with knowledge in a short period of time. Nevertheless, it is an efficient learning technique and its outcome can be determined as part of the lesson content by employing suitable means of assessment such as tests and quizzes [22]-[24].

The main characteristics of micro-learning are that less time is spent on each lesson, the duration of which can be as short as a few seconds and should not be more than 15 minutes. Further, the learning should be directly aimed at the learners' requirements and may be presented in various formats through a variety activities, such as videos, quizzes, games, or interactive multimedia [5], [17]. In addition, micro-learning is conducted through mobile devices which can be conveniently carried anywhere and thus, learning can be performed at any place and at any time [6], [25]. Many previous studies have investigated how the concept of micro-learning can be used for both formal and informal learning/training in a variety of learning domains [26]-[30].

However, some problems have been identified in regard to micro-learning through hand-held devices including the difficulty of organizing content to accommodate mobile devices' technical ability to present it in the limited learning time available [25], [31]-[33], and designing systems to interact with peer learners and to facilitate collaborative or community learning [34]-[36]. Thus, a mangrove ecology self-learning application was focused on the design of both the content and the activities through which it was presented as well as the design of the overall system. The content and activities needed to be presented in short lessons and micro-activities, and in particular, the design of the content of the lessons aimed to help the learners to construct self-knowledge rather than merely consume knowledge.

Moreover the design of a system enabled learners to connect with their peers from whom they can obtain help and to collaborate with a wider community of learners, while teachers could be actively engaged and show their presence in the system [37]. Social media was used as the medium of communication and the means of exchanging knowledge with others [38]-[40]. Moreover, practical problem-solving activities e.g., posting questions and answers, sharing learner's experiences, uploading photographs and video content were also employed consistent with the aim of this study of enabling learners to understand mangrove forest ecology while creating awareness of the environmental issues involved, using a format which facilitated self-learning through short lessons consistent with learners' limited attention span available on mobile devices, at any time or place.

\section{Basic Requirements for Designing a Mangrove Ecology Self- Learning Application Based on a Micro-Learning Approach}

According Buchem and Hamelmann [5], Figure 1 shows the basic requirements for designing and developing the self-learning application based on a micro-learning approach. Since micro-learning differs from traditional learning in terms of its concept, methods and its main components, as mentioned above, the following are aspects that 
needed to be considered in developing the system for the mangrove ecology self-leaning application.

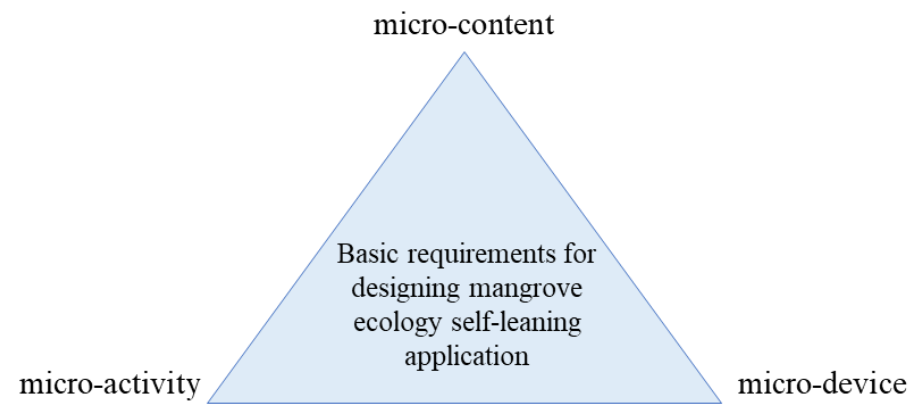

Fig. 1. Basic requirements for designing a self-learning application based on the micro-learning approach (Adapted from [5])

Requirement 1: designing micro-content. The micro-content should be designed in the form of single content units, which are easy to comprehend within a short period of time and should employ a variety of formats in order to attract learner's attention [32], [41], [42]. The quantity and quality of information should be appropriate to be delivered on the mobile device [21].

The main purpose of the micro-content is to create understanding of mangrove forest ecology through self-learning. As mentioned above, this research was based on a case study at Leeled mangrove forest in Surat Thani which represented its content, with the aim of allowing young people to conduct self-learning relating to mangrove forest ecology, and thus, to increase their awareness regarding the importance of preserving mangrove forests.

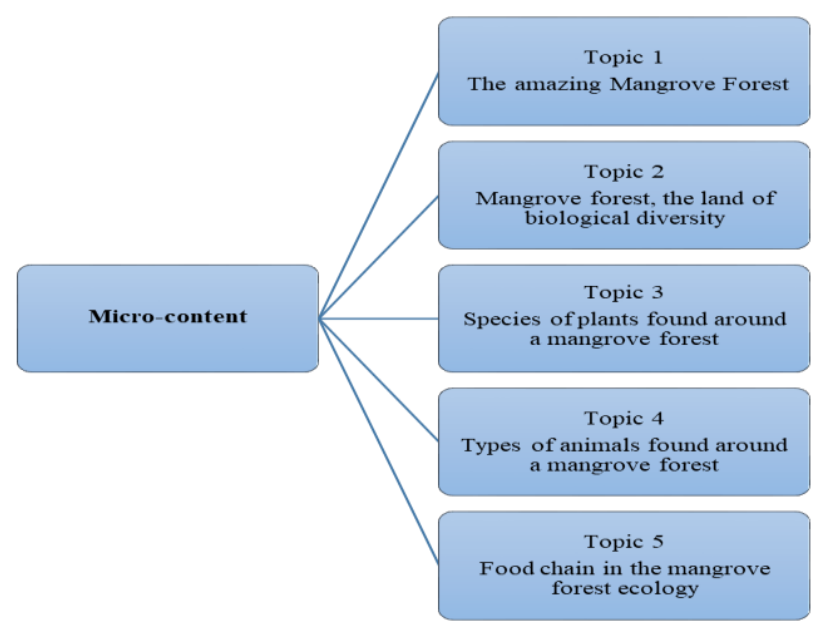

Fig. 2. Micro-content of a mangrove ecology self-learning application in the Leeled mangrove forest 
The topics covered in the application are shown in Figure 2 and the organization of the micro-content aimed to help learners plan their learning based on the time, available to them, such as, while travelling, during lunch breaks, etc. The outcome of microlearning will be better if learners are not forced to study over extended periods involving attending to extensive content with which they might become bored, and which they may not completely absorb. Since human beings have a limited attention span, shorter periods of learning should lead to more complete learning than longer ones. Each topic within the application content shown in Figure 2, would therefore occupy learners for not more than 5-10 minutes and they can decide the order in which they study the topics.

Requirement 2: designing micro-activity focused on the activity must be of limited duration. They must be suitable for presentation on a small-screen electronic device. The focus of the activities is on simple self-learning to develop learners' knowledge and skills through learning the topics. The learning cycle is dynamic with a flexible structure [30], [37], [43], [44].

The activities in the mangrove ecology self-learning application were aimed at young people and must be able to stimulate learners' interest and participation in order to facilitate self-learning. Thus, the main purposes of the design of the micro-activities were to enable them to be studied within a short period of time, anywhere and anytime, and above all, to be capable of focusing learners' attentions on the content. Example of micro-activity are videos, interactive multimedia, games, short texts, infographics and quizzes.

Requirement 3: usable with a variety of devices [31], [45]. The system was designed to be compatible with a variety of devices with a small screen. Accordingly, the first phase of the system was able to be used on mobile devices using the Android Operating System which is both popular and allowed the system to be easily upgraded with the potential for increasing the numbers of users.

\section{Design Thinking Integrated in Software Design}

Design Thinking (DT) is a design methodology that provides an approach to solving problems and seeks to empathize users, problem assumptions, define problems and create innovative solutions to prototype and test [46]. This research applied DT in the system development process which ensures that users' real problems are understood and accommodated in the system. It takes the form of gathering users' ideas and perceptions and developing means of solving the actual problems they identify [47], [48]. It is a way of creating innovative, user-centered ideas in a system and creating a process that seamlessly connects the generation of innovative ideas with their implementation. Its core strength is the constant striving for user feedback on prototypes in order to iteratively shape a final solution that provides the maximum benefit for end users [47], [48].

In this study, DT was used to support the design of the system by involving potential users in the design process and by basing the design on defining both problems and their solutions. After the system was designed, it was tested and the users' feedback obtained and was directed at the most salient features of the system. The five stages of DT [46]-[49] performed was as following. 
The Empathizing user stage entailed understanding the actual needs and problems involved in learning about mangrove forest ecology. It was conducted by collecting data based on a questionnaire and interviews with undergraduate students at Prince of Songkla University, aged between 15 and 25. The result was information about what young users need and want, how they behave, feel and think, why they demonstrate when interacting with the artefacts.

In the defining problems stage, after the data had been collected, the needs and problems were analyzed together with the potential users and the functional requirements were determined. The result was to identify the real needs and problems and the establishing features, functions, and other elements to solve the problems.

After that, the ideating solution stage was stakeholders' brainstorming to look for solutions to users' needs and problems. The result was a system design organized to accommodate the problems identified between the researchers and the potential users.

In the creating prototype and test stage, ideas were transformed and developed into a prototype system. The prototype was tested to see whether it was able to actually solve users' problems and needs. The prototype was later corrected and retested to ensure that it could respond to users' requirements correctly and completely, prior to being developed into an actual system. Finally, the prototype was tested with potential users to obtain their feedback prior to further correction and development into an application that was capable of being used. The result was the prototype of mangrove ecology selflearning application.

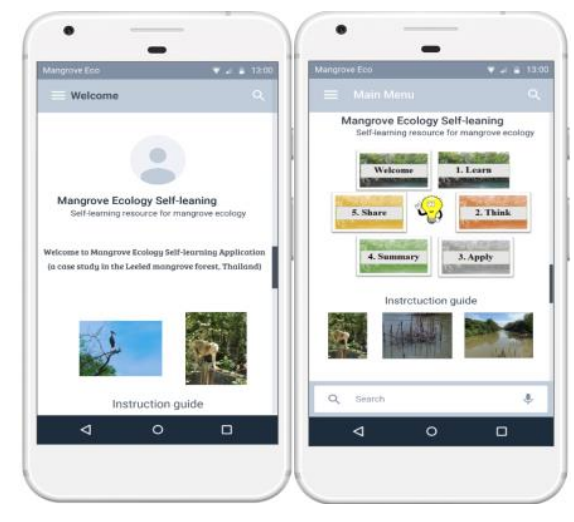

a) Welcome

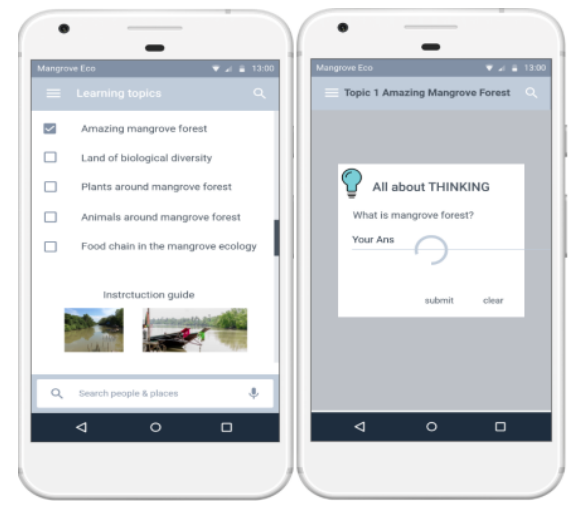

b) Discovery

Fig. 3. The prototype of Mangrove Ecology Self-Learning Application

The prototype is illustrated in Figure 3, and the system comprises of welcome, discovery, and summary sections. Welcome section (Figure 3 (A)) attempts to provide motivation to enter the content, and is in the form of short videos, infographics, and a diagnostic quiz. In the discovery or the learn-think-apply sections consist of objective, content, example, and activity where the content is divided into five individual short topics (Figure 3 (B)) aimed to be precise, easy to understand and fun for the learners so 
that they can undertake self-learning efficiently, and in which the content is presented in the form of games, videos, audio quizzes, etc. The summary and share sections represent the learning conclusion and provides access to peer-learning through an online forum on which learners can seek help and share and post their own materials.

This prototype was tested based on an observation and a questionnaire with the group of undergraduate students (aged between 15 and 25). Participants were to observe and listened to feedback how they use this prototype and how they handle and interact with it provided valuable learning outcomes. The result was to get feedback about the participants' experience and refined this prototype of mangrove ecology self-learning application.

Therefore, a prototype of the mangrove ecology self-learning application was developed for this study which consists of contents and activities aimed at making learners pay more attention to their outside-classroom learning about mangrove forest ecology conducted during their free time on mobile devices, such as smartphones, tablets etc. Learners can also choose the content they wish to view based on their interests and preferences as well as their level of skills. The application therefore makes a contribution to users' lifelong learning.

\section{Discussion and Conclusion}

Digital technology can be used to create perceptions and support strategic self-learning outside the classroom, and thus contributes to lifelong learning. Through technology, innovative learning formats and relevant content can transform the learning process to suit the behaviours of the target learners [5], [6]. Nowadays, young people's behaviours and interests have been changed by technological advancement and this has affected their learning efficiency [10], [50]. These changes open the door to microlearning, with content being easy to understand, of short duration and consisting of only what is relevant to what is being taught.

Previous researchers have studied and designed different approaches for formal and informal learning; however, there are still problems associated with designing microlearning systems for mobile devices for various reasons. The first problem concerns the organization of suitable content which is both short and precise [25], [31]-[33]. The second problem is designing a system that enables interaction by users with their peers, thus facilitating collaborative or community learning [34]-[36]. The third issue is the need to use social media as the means of exchanging knowledge with other learners [38]-[40].

The basic functional requirements for designing a mangrove ecology self-learning application based on the micro-learning approach were determined in this study by focusing on micro-content, micro-activity, and micro-device as well as the analysis of data derived from potential user's ideas, and a design thinking process which ensured that actual problems or requirements were comprehended when designing the system. Consequently, as the design was mainly focused on young learners, the development 
of the mangrove ecology self-learning application emphasized the incorporation of content and activities, and a prototype system was developed in line with the research objectives.

In that prototype, the aim of promoting informal learning with the application was instantiated, and the application enables learners to learn according to their interests and requirements while the problem of limited attention span was also accommodated by restricting the length of study units. Using the application, learners are able to conduct self-learning on their mobile devices at their convenience and in order to encourage learners to understand mangrove forest ecology and be aware of the existing environmental problems, the contents and activities are divided into sub-activities, the duration of which is not more than 15 minutes.

Further, all the content is capable of being presented on mobile device. The content is designed of to be relevant and concise, as well as being easy for learners to understand, with the activities being stimulating and cognitively demanding, including using such mental processes as investigating and implementing, thus creating selfknowledge. The system also allows access to other users through Facebook and thereby facilitates collaborative learning.

Therefore, the benefits and values of the mangrove ecology self-learning application developed are the fact that young learners can conduct self-learning and self-practice or gain experience from real performance which differs from knowledge gained in the classroom from books or lecturers. The self-learning application is a tool which allows users to integrate learning activities into their daily routine, with self-learning leading to lifelong learning. However, there are some limitations to this research: firstly, this is the initial phase of the development of the mangrove ecology self-learning application and the results described relate only to the prototype system developed, which will be further developed into a final system, which will then be evaluated by potential users. Secondly, the findings described in this paper are specific to the case study of a mangrove forest in the south of Thailand and it would be difficult to apply them to other contexts. Moreover, since the system designed and the analysis of needs were focused on learning by young people, the same design and analysis might not be applicable to older age-groups.

\section{References}

[1] N. Pumijumnong, "Mangrove Forest in Thailand," in Mangrove Ecosystems of Asia: Status, Challenges and Management Strategies, I. Faridah-Hanum, A. Latiff, K. R. Hakeem, and M. Ozturk, Eds. New York: Springer, 2014, pp. 61-80. https://doi.org/10.1007/978-1-4614$\underline{8582-7}$

[2] T. Naito and S. Traesupap, "The relationship between mangrove deforestation and economic development in Thailand," in Mangrove Ecosystems of Asia: Status, Challenges and Management Strategies, I. Faridah-Hanum, A. Latiff, K. Hakeem, and M. Ozturk, Eds. New York: Springer, 2014, pp. 273-294. https://doi.org/10.1007/978-1-4614-8582-7

[3] P. H. Hung, Y. F. Lin, and G. J. Hwang, "Formative assessment design for PDA integrated ecology observation,” Educ. Technol. Soc., vol. 13, no. 3, pp. 33-42, 2010. 
[4] M. Ruchter, B. Klar, and W. Geiger, "Comparing the effects of mobile computers and traditional approaches in environmental education," Comput. Educ., vol. 54, no. 4, pp. 10541067, 2010. https://doi.org/10.1016/j.compedu.2009.10.010

[5] I. Buchem and H. Hamelmann, "Microlearning: a strategy for ongoing professional development Microcontent and Microlearning," eLearning Pap., vol. 21, no. September 2010, pp. $1-15,2010$.

[6] X. Gu, F. Gu, and J. M. Laffey, "Designing a mobile system for lifelong learning on the move," J. Comput. Assist. Learn., vol. 27, no. 3, pp. 204-215, 2011. https://doi.org/10. $\underline{1111 / \mathrm{j} .1365-2729.2010 .00391 . \mathrm{x}}$

[7] F. Khaddage, W. Müller, and K. Flintoff, "Advancing mobile learning in for-mal and informal settings via mobile app technology: Where to from here, and how?" Educ. Technol. Soc., vol. 19, no. 3, pp. 16-26, 2016.

[8] T. Seidel, "The role of student characteristics in studying micro teaching-learning environments," Learn. Environ. Res., vol. 9, no. 3, pp. 253-271, 2006. https://doi.org/10.1007/ $\underline{\text { s10984-006-9012-X }}$

[9] L. F. M. G. Pedro, C. M. M. de O. Barbosa, and C. M. das N. Santos, "A critical review of mobile learning integration in formal educational contexts," Int. J. Educ. Technol. High. Educ., vol. 15, no. 1, 2018. https://doi.org/10.1186/s41239-018-0091-4

[10] TCDC, "The world trend 2019 by TCDC NOW AGE: Manifesto and Action," Bangkok, 2019.

[11] O. Jomah, A. K. Masoud, X. P. Kishore, and S. Aurelia, "Micro Learning: A Modernized Education System,” BRAIN. Broad Res. Artif. Intell. Neurosci., vol. 7, no. 1, pp. 103-110, 2016.

[12] G. S. Mohammed, K. Wakil, and S. Sirwan Nawroly, "The Effectiveness of Microlearning to Improve Students' Learning Ability,” Int. J. Educ. Res. Rev., vol. 3, no. 3, pp. 32-38, 2018. https://doi.org/10.24331/ijere.415824

[13] L. C. Emerson and Z. L. Berge, "Microlearning: Knowledge management applications and competency-based training in the workplace," Knowl. Manag. E-Learning, vol. 10, no. 2, pp. 125-132, 2018. https://doi.org/10.34105/j.kmel.2018.10.008

[14] S. Sathirathai and E. B. Barbier, "Valuing mangrove conservation in Southern Thailand," Contemp. Econ. Policy, vol. 19, no. 2, pp. 109-122, 2001. https://doi.org/10.1111/j.14657287.2001.tb00054.x

[15] W. Giesen, S. Wulffraat, M. Zieren, and L. Scholten, Mangrove Ecosystems of Asia. Bangkok: FAO Regional Office for Asia and the Pacific, 2014.

[16] J. E. Ong, "Strategies for Sustainable Mangrove Management and Conservation," J. For. Manag., vol. 6, no. 11, pp. 1-12, 2012.

[17] J. Van Bruggen, “Theory and practice of online learning,” Br. J. Educ. Tech-nol., vol. 36, no. 1, pp. 111-112, 2005.

[18] N. A. Bradbury, "Attention span during lectures: 8 seconds, 10 minutes, or more?” Adv. Physiol. Educ., vol. 40, no. 4, pp. 509-513, 2016. https://doi.org/10.1152/advan.00109. $\underline{2016}$

[19] K. R. Subramanian, "Myth and mystery of shrinking attention span," Int. J. Trend Res. Dev., vol. 5, no. 3, pp. 1-6, 2018.

[20] G. Gassler, T. Hug, and C. Glahn, "Integrated Micro Learning - An outline of the basic method and first results," Interact. Comput. Aided Learn., pp. 1-7, 2004.

[21] T. Hug, "Mobile Learning as 'Microlearning': Conceptual Considerations towards Enhancements of Didactic Thinking," Int. J. Mob. Blended Learn., vol. 2, no. 4, pp. 47-57, 2010. https://doi.org/10.4018/jmbl.2010100104 
[22] M. Rao, "Microlearning from the KM perspective," KM World, vol. 23, no. 2, pp. 1-20, 2014.

[23] B. Aitchanov, A. Nussipbekov, and M. Zhaparov, "Microlearning of web fundamentals based on mobile learning," Int. J. Comput. Sci. Issues, vol. 9, no. 6, pp. 148-150, 2012.

[24] H. H. Yang, "New World, New Learning: Trends and Issues of E-Learning," Procedia - Soc. Behav. Sci., vol. 77, pp. 429-442, 2013.

[25] T. Javorcik and R. Polasek, "The Basis for Choosing Microlearning Within the Terms of ELearning in the Context of Student Preferences," in 2018 16th International Conference on Emerging eLearning Technologies and Applications (ICETA), 2018, pp. 237-244. https://doi.org/10.1109/iceta.2018.8572183

[26] H. Kadhem, "Using mobile-based micro-learning to enhance students; Retention of IT concepts and skills," in 2017 2nd International Conference on Knowledge Engineering and Applications (ICKEA), 2017, vol. Jan 2017, pp. 128-132. https://doi.org/10.1109/ickea. 2017.8169915

[27] J. Skalka and M. Drlík, "Conceptual framework of microlearning-based training mobile application for improving programming skills," in Advances in Intelligent Systems and Computing, 2018, vol. 725, pp. 213-224. https://doi.org/10.1007/978-3-319-75175-7_22

[28] S. Cates, D. Barron, and P. Ruddiman, "MobiLearn Go: Mobile microlearning as an active, location-aware game," in Proceedings of the 19th International Conference on Human-Computer Interaction with Mobile Devices and Services, 2017. https://doi.org/10.1145/ $\underline{3098279.3122146}$

[29] G. Kovacs, "FeedLearn: Using facebook feeds for microlearning," in Conference on Human Factors in Computing Systems - Proceedings, 2015, vol. 18, pp. 1461-1466. https:// doi.org/10.1145/2702613.2732775

[30] L. P. A. Simons, F. Foerster, P. A. Bruck, L. Motiwalla, and C. M. Jonker, "Microlearning mApp raises health competence: hybrid service design," Health Technol. (Berl)., vol. 5, no. 1, pp. 35-43, 2015. https://doi.org/10.1007/s12553-015-0095-1

[31] J. Carter, "Expanding access to learning with mobile digital devices," J. Res. Pract. Adult Literacy, Second. Basic Educ., vol. 6, no. 2, pp. 49-54, 2017.

[32] Y. Park and Y. Kim, "A design and development of micro-learning content in e-learning system," Int. J. Adv. Sci. Eng. Inf. Technol., vol. 8, no. 1, pp. 56-61, 2018.

[33] C. Demmans Epp and K. Phirangee, "Exploring mobile tool integration: De-sign activities carefully or students may not learn," Contemp. Educ. Psychol., vol. 59, pp. 1-17, 2019. https://doi.org/10.1016/j.cedpsych.2019.101791

[34] R. Kaliisa and M. Picard, "A systematic review on mobile learning in higher education: The African perspective,” Turkish Online J. Educ. Technol., vol. 16, no. 1, pp. 1-18, 2017.

[35] M. Bower, M. J. W. Lee, and B. Dalgarno, "Collaborative learning across physical and virtual worlds: Factors supporting and constraining learners in a blended reality environment," Br. J. Educ. Technol., vol. 48, no. 2, pp. 407-430, 2017. https://doi.org/10.1111/ bjet. 12435

[36] S. A. Nikou and A. A. Economides, "Mobile-Based micro-Learning and Assessment: Impact on learning performance and motivation of high school students," J. Comput. Assist. Learn., vol. 34, no. 3, pp. 269-278, 2018. https://doi.org/10.1111/jcal.12240

[37] I. Jahnke, Y.-M. Lee, M. Pham, H. He, and L. Austin, "Unpacking the Inherent Design Principles of Mobile Microlearning," Technol. Knowl. Learn., pp. 1-33, 2019. https:// doi.org/10.1007/s10758-019-09413-w

[38] C. W. Shen, C. J. Kuo, and P. T. M. Ly, "Analysis of social media influencers and trends on online and mobile learning,” Int. Rev. Res. Open Distance Learn., vol. 18, no. 1, pp. 1-224, 2017. https://doi.org/10.19173/irrodl.v18i1.2640 
[39] Y. Grevtseva, J. Willems, and C. Adachi, "Social media as a tool for micro-learning in the context of higher education," in Proceedings of the 4th European Conference on Social Media, ECSM 2017, 2017, pp. 131-139.

[40] S. Lambert, C. Antomarchi, K. Johnson, J. Stevenson, M. Debulpaep, and T. Katrakazis, "Preventive Conservation on Demand: Developing Tools and Learning Resources for the Next Generation of Collections Professionals," Stud. Conserv., vol. 63, no. sup1, pp. 156163, 2018. https://doi.org/10.1080/00393630.2018.1476961

[41] C. Wen and J. Zhang, "Design of a Microlecture Mobile Learning System Based on Smartphone and Web Platforms," IEEE Trans. Educ., vol. 58, no. 3, pp. 203-207, 2015. https://doi.org/10.1109/te.2014.2363627

[42] K. Yu, "Design and application of micro-video course recording in 'General city planning' course,” Int. J. Emerg. Technol. Learn., vol. 11, no. 5, pp. 16-21, 2016. https://doi.org/10. 3991/ijet.v11i05.5687

[43] M. I. F. Souza and S. F. do Amaral, "Educational Microcontent for Mobile Learning Virtual Environments," Creat. Educ., vol. 05, no. 09, pp. 672-681, 2014. https://doi.org/ $10.4236 / \mathrm{ce} .2014 .59079$

[44] N. Gao, "Construction and implementation of teaching mode for digital mapping based on interactive micro-course technology," Int. J. Emerg. Technol. Learn., vol. 13, no. 2, pp. $21-$ 32, 2018. https://doi.org/10.3991/ijet.v13i02.8317

[45] F. J. García-Peñalvo and M. Conde, "The impact of a mobile personal learning environment in different educational contexts," Univers. Access Inf. Soc., vol. 14, no. 3, pp. 375-387, 2015. https://doi.org/10.1007/s10209-014-0366-Z

[46] J. C. Pereira and R. de F. S. M. Russo, "Design thinking integrated in agile software development: A systematic literature review," in Procedia Computer Science, 2018, vol. 138, pp. 775-782. https://doi.org/10.1016/j.procs.2018.10.101

[47] A. Wölbling, K. Krämer, C. N. Buss, K. Dribbisch, P. LoBue, and A. Taherivand, "Design Thinking: An Innovative Concept for Developing User-Centered Software," in Software for People, Alexander Maedche, A. Botzenhard, and L. Neer, Eds. Berlin, Heidelberg: Springer, 2012, pp. 121-136. https://doi.org/10.1007/978-3-642-31371-4_7

[48] F. Häger, T. Kowark, J. Krüger, C. Vetterli, F. Übernickel, and M. Uflacker, "DT@Scrum: Integrating Design Thinking with Software Development Processes," in Design Thinking Research: Understanding Innovation, H. Plattner, L. J. Leifer, and C. Meinel, Eds. Springer, Cham, 2015, pp. 263-289. https://doi.org/10.1007/978-3-319-06823-7_14

[49] R. Kraleva, "Designing an interface for a mobile application based on children's opinion," Int. J. Interact. Mob. Technol., vol. 11, no. 1, pp. 53-70, 2017. https://doi.org/10.3991/ ijim.v11i1.6099

[50] K. N. Chee, N. Yahaya, N. H. Ibrahim, and M. N. Hasan, "Review of mobile learning trends 2010-2015: A meta-analysis,” Educ. Technol. Soc., vol. 20, no. 2, pp. 113-126, 2017.

\section{$7 \quad$ Authors}

Supaporn Chai-Arayalert is a lecturer in the Department of Applied Mathematics and Information Systems within the Faculty of Science and Industrial Technology at Prince of Songkla University, Thailand. Her current research interests include knowledge management, Green IT, IT project management, e-commerce, and business information systems. 
Supattra Puttinaovarat is an assistant professor at Faculty of Science and Industrial Technology, Prince of Songkla University, Surat Thani Campus. Her research interest includes Geographic Information System, Remote Sensing and Information Technology.

Article submitted 2019-12-02. Resubmitted 2020-02-13. Final acceptance 2020-02-21. Final version published as submitted by the authors. 